\title{
Exploring Local Perceptions of and Attitudes toward Endangered François' Langurs (Trachypithecus francoisi) in a Human-modified Habitat
}

Authors: Kefeng Niu ${ }^{1,2,10}$, Wei $\mathrm{Liu}^{3}$, Zhi Xiao ${ }^{4,5}$, Ankang Wu , Tianyou Yang $^{6}$, Isidoro

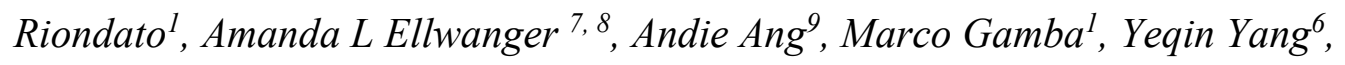
Cristina Giacoma ${ }^{1}$

1 Department of Life Sciences and Systems Biology, University of Turin, Turin, 10123, Italy

2 Fanjingshan National Nature Reserve Administration, Tongren, 554400, PR China

3 International Institute for Applied Systems Analysis, Laxenburg, A-2361, Austria

4 Mayanghe National Nature Reserve Administration, Tongren, 565300, PR China

5 Renhuai Forestry Administration, Zunyi, 564500, PR China

6 Primate Conservation Research Institute, Tongren University, Tongren, 554300, PR China

7 Department of Anthropology, University of Texas at San Antonio, San Antonio, Texas, United States

8 Department of Cultural and Behavioral Sciences, Georgia State University Perimeter College, Dunwoody, Georgia, United States

9 Raffles' Banded Langur Working Group, Wildlife Reserves Singapore, 711 Yishun Avenue 5, 760711, Singapore

10 Institute of Eastern-Himalaya Biodiversity Research, Dali University, Dali, 671003, PR China 
Corresponding author: Kefeng Niu, Department of Life Sciences and Systems Biology, University of Turin, Via Accademia Albertina 13, 10123 Turin, Italy.

Tel. +8613176481930

Email: niukf@eastern-himalaya.cn

Running title: Local Perceptions of and Attitudes toward Trachypithecus francoisi

\section{Data Availability}

The datasets analyzed during the current study are available from the corresponding author on reasonable request.

\section{Acknowledgement}

We thank UNI.COO Project (No.: 27164) of University of Turin, Italy and Primate Conservation Inc., USA (No.: PCI \#1394) for funding this survey. We appreciate the editor-in-chief, Dr. Joanna Setchell, so much for her great support in submission of this longer manuscript. We are grateful to Dr. Joanna Setchell and three anonymous reviewers for their excellent comments on an earlier version of this manuscript. We thank the Department of Guizhou Forestry, MNNR Administration and the Qinglong community committee for permissions to implement this survey in Qinglong village, China. We want to give our sincere thanks to all the respondents in Qinglong village who graciously participated in this research. During the survey, we received invaluable support from Director Weiyong Zhang (Fanjingshan National Nature Reserve Administration), Director Luming Wei (MNNR), 
Guoyong Xiao, Zhijin Xiao and Bo Liu in Qinglong village, and staff members Lei Shi (FNNR), Qixian Zou, Peng Zhang, Xiugang Yan and Xiaolin Mao (MNNR). We would like to express our gratitude to Shaoguo Peng from Hongyan village and Peng Yang, Lianlian Luo, Qunfeng $\mathrm{Wu}$, and Chong Ran from Tongren University for their assistance with interview surveys. We are lucky to have the help from Dr. Chia L. Tan (LVDI International, USA) and Qi Mu (Politecnico di Torino, Italy) on the project and manuscript preparation. Special thanks to the "San Paolo Company (Compagnia di San Paolo)" Foundation for support of Niu's Ph.D. Scholarship in University of Turin, Italy.

Author Contributions: KN, TY, ZX, AW and YY designed questionnaire, KN and TY collected the data, $\mathrm{KN}$ and $\mathrm{WL}$ analyzed the data and developed methodology, $\mathrm{KN}$ led the writing with contributions from WL and ALE. AA, CG, MG and IR provided editorial advice and revised it for accuracy and content, and all the authors approved the final version of the manuscript.

\section{Compliance with Ethical Standards}

Conflict of Interest: The authors declare that they have no conflict of interest. 
1 Title: Exploring Local Perceptions of and Attitudes toward Endangered François' Langurs

2 (Trachypithecus francoisi) in a Human-modified Habitat

3 Abstract Understanding local community attitudes toward wildlife is critical for making

4 context-sensitive conservation planning and management decisions that may facilitate better

5 human-wildlife coexistence. We conducted questionnaire-based interviews with local

6 households in the Qinglong village of Mayanghe National Nature Reserve (MNNR) in

7 China from March to August 2015. We used a mixed analysis technique based on a

8 theoretical framework of categorical variables to explain attitudes to investigate the key

9 factors that influenced local attitudes toward Endangered François' langurs (Trachypithecus

francoisi). We found that 53\% $(40, N=75)$ of interviewees liked François' langurs presence around the village; $27 \%$ did not; and $20 \%$ were neutral. Respondents with favorable attitudes to langurs associated them mainly with tangible benefits from local tourism and their positive aesthetic and emotional values. Respondents with negative attitudes to langurs associated them with tangible costs such as crop feeding and the destruction of their houses. Over half $(N=9)$ of respondents with neutral attitudes associated langurs with various cost and benefit trade-offs. Overall, local people tended to have slightly negative perceptions of the langurs' impacts at the household level, while they had very positive perceptions of their impacts at the community level. Ordinal logistic regression models revealed that age, gender, and impact perceptions were significantly associated with local residents' attitudes towards the langurs at the household and community levels. We suggest that such socioeconomic monitoring efforts should be periodically conducted in protected areas like MNNR, especially in the context of rapid economic and infrastructure development. 
Key words: Local Attitudes and Perceptions $\cdot$ Human and Primate Co-existence $\cdot$ Primates Conservation · Ethnoprimatology · China · Theoretical Framework of Categorical Variables $\cdot$ Perceived cost and benefit

\section{INTRODUCTION}

Humans have been identified as a substantial causal factor of the sixth mass extinction (Ceballos et al. 2015; Corlett 2015). To promote effective conservation of biodiversity for the maintenance of ecosystem processes and for human survival, it is essential to understand the interactions between wildlife species and the relevant stakeholders (Manfredo 2008; Rands et al. 2010). The local community is one of the most important stakeholders in wildlife conservation and protected area management because local people share the ecosystem with wildlife and interact with it (Nepal 2002). The livelihood needs of local people, desires for economic development, and top-down approaches to conservation have led to low participation of local people in wildlife conservation in most developing countries (Abrams et al. 2009; Adams et al. 2004). The relationship between local residents and wildlife may be additionally strained when there is conflict between them (e.g. Lee and Priston 2005). For conservation initiatives to succeed, we need to understand human-wildlife relations and incorporate local stakeholders in the decision-making process through evidence-based management (Nepal 2002).

Attitudes can be defined as an individual's disposition to respond with some degree of favorableness, or not, to an object, person, or event, or any other discriminable aspect of the individual's world (Ajzen and Fishbein 1980). Understanding the factors which shape 
attitudes towards human-wildlife conflict is important in predicting human behavior and mitigating conflict (Manfredo and Bright 2008). Individuals' attitudes toward animals may vary with the needs of the person and the degree to which they perceive these needs have been met (Manfred 1991; Maslow 1943). This leads to a complex psychological determinant system with diverse variables involved (e.g. intangible and tangible cost and benefit perceptions, knowledge of wildlife, exposure and experience with wildlife, species characteristics, socio-demographic variables) (Kansky and Knight 2014). The perceived costs and benefits of wildlife have generally been considered the primary determinants of attitudes toward wildlife (Chan et al. 2007; Linnell et al. 2010). A meta-analysis of the variables predicted to affect the attitudes of people living in areas with wildlife towards large mammals found that intangible costs were the most important category of factors explaining people's attitudes (Kansky and Knight 2014). However, this conclusion may have some limitations as the majority of publications were studies involving carnivores (Kansky and Knight 2014)

The relative importance of cost and benefit categories and other categories to explain attitudes may vary for different animal species (Kansky and Knight 2014). Interactions between wildlife and people varied across a wide range of contexts (Kansky et al. 2014). If researchers do not include a comprehensive range of interactions in their studies, results concerning local people's attitudes towards wildlife might not reflect their actual perceptions. Researchers often focus on costs or conflicts rather than benefits when attempting to understand people's attitudes toward wildlife (Kansky and Knight 2014; Sekhar 2003). However, tangible benefits may be very important, especially if the species contributes 
positively towards people's livelihoods (Sekhar 2003). For example, infrastructure development programs to support sustainable wildlife use in critical habitats may contribute tangible benefits for local people. If these efforts are linked with conservation initiatives, they can create positive conservation attitudes (Ellwanger et al. 2015; Xiang et al. 2011). In addition, the importance of intangible costs, such as the hidden health, opportunity and transaction costs of human-wildlife conflict has been recognized recently (Barua et al. 2013) while intangible benefits such as positive emotions, aesthetic or cultural values as well as ecosystem services have been less explored (Kansky and Knight 2014). By incorporating a range of variables to investigate what influences attitudes (e.g. intangible costs or benefits), we can improve our understanding of how attitudes shape conservation outcomes.

Nonhuman primates (hereafter primates) are a salient aspect of the environment for human communities that share space with these animals (Estrada et al. 2017; Hvenegaard 2014; Lee and Priston 2005). Local people's perceptions of and attitudes towards primates have received considerable attention (e.g. Alexander 2000; Chalise and Johnson 2005; Knight 1999; Lee and Priston 2005). More recently, studies using an ethnoprimatological approach have demonstrated that a comprehensive framework for understanding the dynamic interactions between local stakeholders with different attitudes and sympatric primate species can mitigate conflict and promote co-existence (e.g. Fuentes and Hockings 2010; Riley and Priston 2010; Setchell et al. 2017; Sousa et al. 2014). Similar to Kansky and Knight's (2014) conclusion, several studies have showed that a negative emotional connection (i.e., fear of animals) might shape negative perceptions of species (Campbell-Smith et al. 2010; Sousa et al. 2014). In other cases, the animals' human-like appearance and behavior or positive 
traditional folklore inform positive perceptions of primates (e.g. Costa et al. 2013; Dore et al. 2018a; Riley and Priston 2010; Xiang et al. 2010). Some researchers have examined how crop foraging or the economic benefits of ecotourism can influence local residents' perceptions of and attitudes toward endangered primates (Ellwanger et al. 2015; Hill 2000; McLennan and Hill 2013; Setchell et al. 2017; Sousa et al. 2014). When crop foraging was associated with more negative perceptions of the species concerned, the perceived benefits of primate-based tourism provided balance to attitudes, likely positively influencing the human-primate relationship (Ellwanger et al. 2015; Hill 2000, 2005; Knight 1999; Xiang et al. 2011). Furthermore, socio-demographic factors (e.g. Ellwanger et al. 2015; Rocha and Fortes 2015) or local knowledge of species (e.g. Ellwanger et al. 2015; Reibelt et al. 2017; Sousa et al. 2014) have been linked with local perceptions of and attitudes toward primates on a case-by-case basis. However, a lack of conceptual clarity to guide the selection of variables in attitudinal research may fail to effectively compare the drivers of attitudes across a broad range of primate species and societies (Kansky and Knight 2014). This makes it difficult to build a comprehensive theory and investigate broader patterns of factors that determine attitudes towards primates or other wildlife. Hence primatologists need a theoretical framework with greater conceptual clarity for future research on attitudes toward primates so as to allow for greater consensus on the identification, categorization, and evaluation of the importance of attitudinal variables across a wide range of studies.

China is home to 1.4 billion people and 693 mammalian species (Jiang et al. 2016, 2017). Over-exploitation by humans, habitat loss and human interference are the three leading threats to many of these animals (Jiang et al. 2016). Among them, 25 species of 
110

111

primates are highly threatened in China (Li et al. 2018). A new national park system has been recently proposed and piloted, with the intention of promoting harmonious coexistence between human and nature (overall plan on the development and management of national parks 2017). In this national plan, local residents in the "gate community", which refers to key communities living near and around national parks, are encouraged to participate in nature education programs and co-management of the ecosystem. Although examining attitudes within a particular context is helpful for wildlife conservation and the engagement of local residents, there are few studies on local perceptions of and attitudes toward primates and other flagship wildlife in China (e.g. Guizhou snub-nosed monkeys Rhinopithecus brelichi, Ellwanger et al. 2015; Asian elephant Elephas maximus, He et al. 2011). Here, we explore local attitudes toward the Endangered François' langur (Trachypithecus francoisi) (Bleisch et al. 2008), based on Kansky and Knight's (2014) theoretical framework of categorical variables. The approach enables the identification of specific and significant variables explaining attitudes to the langurs which would help develop targeted conservation programs in China. It also generates a broader pattern of categorical variables with greater conceptual clarity to explain attitudes for further comparisons across species and across cultures.

\section{METHODS}

\section{Species and Study site}


132

133

locations in the limestone hills and valleys of Northern Vietnam and Southern China (Li et al. 2007; Nadler et al. 2007; Niu et al. 2016). The langurs' survival is mostly threatened by hunting and habitat loss and fragmentation (Hu et al. 2004; Li et al. 2007; Nadler et al. 2007; Niu et al. 2016). Our latest review indicates that the global wild population of François' langur has decreased to around 1,700 individuals and about $70 \%$ of the subpopulations have fewer than 50 individuals (Author in prep.). The François' langur is classified as Endangered by the IUCN Redlist and as a Category I species under the Wildlife Protection Act in China (Bleisch et al. 2008; Niu et al. 2016). The conservation status of this species warrants urgent attention.

Mayanghe National Nature Reserve of China (MNNR, Fig. 1, N28 37'33" $\left.28^{\circ} 54^{\prime} 27^{\prime \prime}, E 108^{\circ} 3^{\prime} 39^{\prime \prime} \sim 108^{\circ} 20^{\prime} 25^{\prime \prime}\right)$ is located at the junction of Yanhe County and Wuchuan County of Guizhou province, one of the poorest regions in China (Zhu et al. 2017). It was established in 1987 as a provincial nature reserve to protect François' langurs and their habitat. In 2003, it was upgraded to a national nature reserve. MNNR is about 31,113 ha, consisting of core (10,543 ha), buffer (10,522 ha) and transition (5,548 ha) zones (Fig. 1) (Zhu et al. 2017). In 2015, there were about 23,000 human residents living in MNNR. Tujia people account for $47 \%$, while the rest of population are Gelao (33\%), Miao (14\%), and Han people (6\%) (Zhu et al. 2017). MNNR is home to the largest free-ranging population (about 554 individuals) of François' langurs in the world and the survival of the langurs in this reserve is key for the conservation of this species (Niu et al. 2016). 


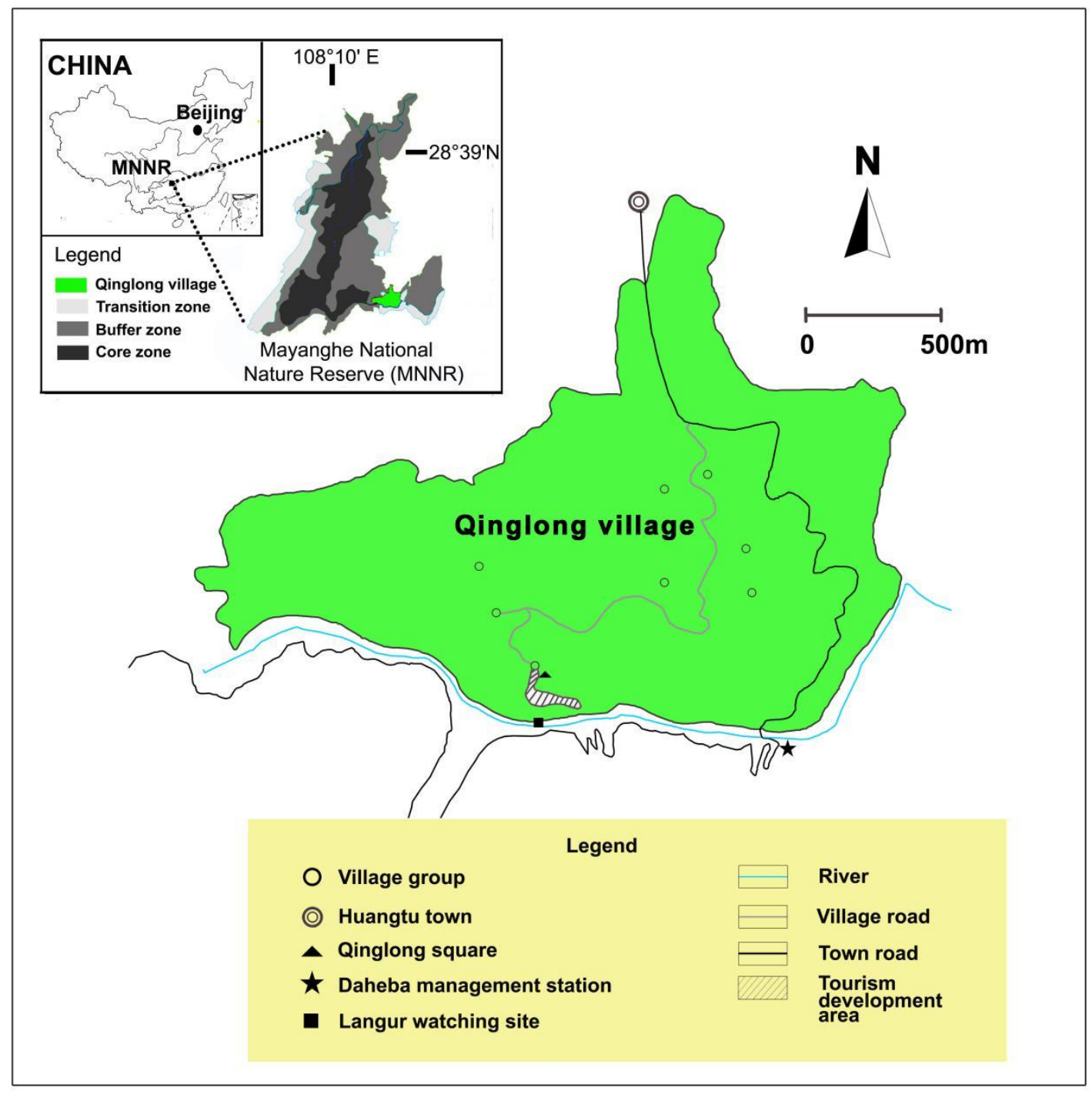

Fig. 1 Qinglong Village and Mayanghe National Nature Reserve in China

Human-langur interactions are common in MNNR. Due to the dense human population and the severe degradation of natural habitats in the reserve, the langurs have been observed to feed on cultivated plants (e.g. corn and sweet potato) and forage in homes, causing considerable crop and property damage (Niu et al. 2016). Local youths injured three langurs to prevent crop damage in 2011 and one langur was killed by a dog in 2013 (Niu et al. 2016; Zhu et al. 2017). To address the complaints of local residents concerning property damage caused by langurs, the reserve administration began to financially compensate local residents 
for economic losses in 2011.

resources (timber and nontimber forest products, hunting, fishing, and mining) in the reserve are strictly for household use or commercial sale. The limited access to natural resources brings considerable opportunity costs (i.e., potential benefits to people that are lost to protect a site for the langur population) to the local community (Barua et al. 2013; Hvenegaard 2014). Human disturbance, including illegal activities, still occurs in the reserve (Zhu et al. 2017). In 2014-2015, up to 40 ha of forest were illegally logged (data from MNNR). Until recently, snares could easily be bought in a nearby market in Huangtu town (Zhu et al. 2017). Wild boar (Sus scrofa) and tufted deer (Elaphodus cephalophus) have been hunted in the past five years (Author, unpubl data; Zhu et al. 2017).

Our study site is Qinglong village in the south of MNNR (Fig. 1 and Fig. 2 a). It is an agricultural village and people plant a variety of cash crops including corn, tobacco, sweet potato, bean, potato, and vegetables (Author, unpubl data). The main grazing animals are cattle, goats, pigs and chickens (Author, unpubl data). At least three groups of François' langurs (32 individuals in total) were observed around this village in 2015 (Fig. 2 b, Author, unpubl data). We selected Qinglong village because it has been a site of several pilot conservation programs and provides a model system to study the relationship between local residents and François' langurs. Beginning in 1997, the MNNR staff habituated a group of François' langurs in Qinglong village through food provisioning with the permission of MNNR administration to study François' langur ecology and develop tourism (Wu 2004). From this point on, more and more tourists come to this village to watch langur. For example, 
185 (October 1-5) in 2016 (Data from MNNR). However, as langur tourism developed without 186 strict guidelines in the village, people often interact with and feed monkeys. Qinglong village 187 is supported by the local county government and MNNR administration to develop a François' 188 langur tourism program; at least 3 million CNY ( US\$ 450,000) has been invested in the 189 construction of infrastructure such as roads, walking paths and a public square in the village 190 since 2011 (Fig. 1). This construction near the river valley may have caused habitat loss for 191 François' langurs in Qinglong village (Niu et al. 2016). 

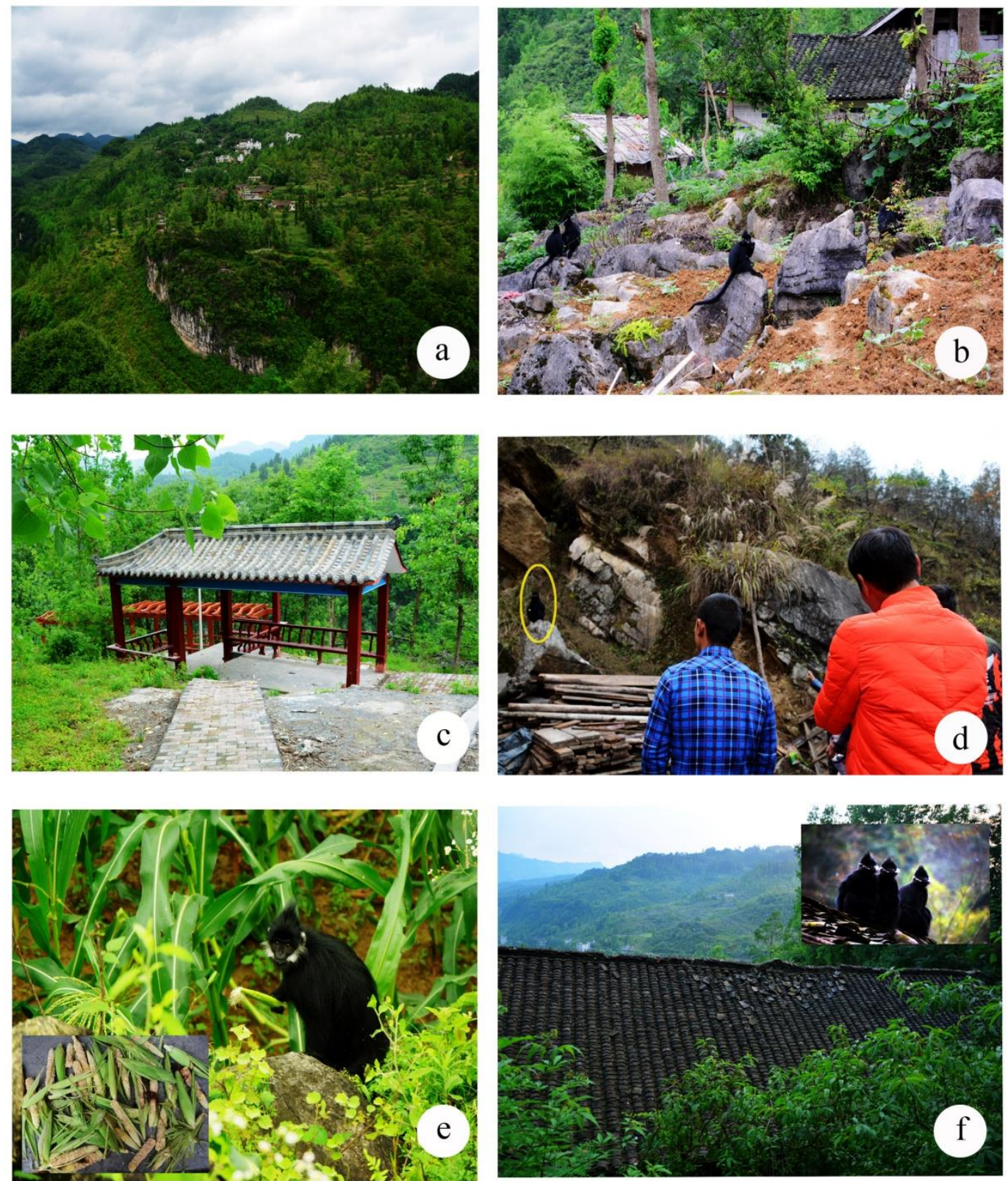

Fig. 2 a A corner of Qinglong Village in Mayanghe National Nature Reserve, China; b François' langurs in Qinglong

Village; $c$ New infrastructure construction in Qinglong village because of the langur-related tourism program; $d$ Local residents and tourists watching François' langurs; e François' langurs feeding on maize crops; f A house damaged by

François' langurs. (Photo: a-d, f by XXX and e by XXX). 

were occupied in the village because over half of the residents were working in the cities during most of the year. This phenomenon may bias our results (Knight 1999; Kansky et al. 2014). Through an online sample size calculator (http://www.surveysystem.com/sscalc.htm), combining confidence interval (also called margin of error; expressed as decimal, e.g., 0.05 $= \pm 5$ ) and $95 \%$ confidence level (The $95 \%$ confidence level means we are $95 \%$ sure that the true percentage of the population who would pick an answer lies within the confidence interval), we determined that a sample size of 86 households would provide a representative sample of the current population in Qinglong village. To obtain this sample size, we tried to interview all the households who were available in the village during our study period. December 2014 with two MNNR staff and three local people to gain a locally informed understanding of the positive and negative aspects of MNNR and François' langurs. Subsequently, we designed a questionnaire that included four parts: 1) socio-demographic information and local beliefs about animals, 2) agricultural income (mainly income generated of MNNR, François' langurs, and views about wildlife crop-feeding, damage and remedies, and 4) local people's perceptions of and attitudes toward François' langurs and MNNR.

\section{Data collection}


questionnaire containing structured, semi-structured, and open-ended questions (Dore et al. 2018b). We interviewed a total of 105 adults. We could not complete all the questions for all respondents due to medical conditions (e.g. deafness), time limitations and some respondents' low desire to participate. Although the local dialect is similar to Mandarin, we hired a local interpreter/facilitator to overcome language and cultural barriers (Ellwanger et al. 2017). This person was not affiliated in any way with the local authorities of Qinglong village or the MNNR administration; to our knowledge, his presence did not have any significant influence on the answers given by the respondents during the interviews.

In attitudinal questions, we used the term "like" (Do you like the François' langur living around your village?) to assess a respondent's degree of positive attitude toward the François' langur (Ajzen and Fishbein 1980; Allendorf 2007; De Boer and Baquete 1998). We divided respondents' answers into positive (like), neutral, and negative (dislike) responses plus unsure. Participants also shared their reasons for selecting their answers.

We also designed ten questions to assess the costs and benefits respondents associated with the langurs in terms of specific interactions between human and langur in the local context (e.g., the impact of langur related tourism) (Barua et al. 2013; Kansky and Knight 2014). We used a 5-point Likert scale to evaluate the degree of costs and benefits in each question: very important benefits, important benefits, no significant benefits or costs from langurs, important costs, and very important costs. We also recorded participants' comments on the types of cost or benefit associated with langurs. 


\section{Attitudinal analyses}

We calculated the percentage of respondents $(N=75)$ that expressed each attitude

type. We used open coding to analyze the open-ended comments in response to attitude questions (Bernard and Ryan 1998; De Boer and Baquete 1998; Ellwanger et al. 2015). We identified specific themes that emerged from interviews with regards to respondent attitudes and created "reason" codes. We grouped these codes by similarity into "reason types" and then classified these reason types into four categories of perceived costs and benefits: tangible benefits, tangible costs, intangible benefits and intangible costs. For conceptual clarity and category definitions, we referred to Kansky and Knight (2014). explaining differing attitudes towards the langurs among respondents, we calculated the frequency and percentage of each reason type and category among positive, neutral, negative attitudes and effective number of respondents.

\section{Perceived costs and benefits of langurs}

Similar to Carter et al. (2014), we consolidated the respondents' responses to cost and benefit questions from a five-point scale to a three-point scale: positive perception included very important benefits and important benefits (coded "1"), neutral responses included no strong impact from langurs (coded "0"), negative responses included important costs and very important costs (coded "-1"). We coded unsure answers as "NA". We 
277 Age: how old the respondent is; the community level. and negative). The independent variables included:

Gender female $=0$, male $=1$; level;

François' langurs. We created an aggregate score based on the ten questions assessing respondent perceptions of cost and benefit and assigned a score to each respondent based on their responses. We then divided these questions into two groups to assess respondent perceptions of costs and benefits relating to the François' langurs at the household level and at

\section{Key factors driving attitudes toward François' langurs}

To further examine the effect of various factors on local people's attitudes towards langurs, we ran an ordinal logistic regression with attitudes at three levels (positive, neutral,

Logit $[P($ Attitudes $\leq j \mid \mathrm{X})]=\alpha_{j}+\beta_{1} \mathrm{X}_{1}+\beta_{2} \mathrm{X}_{2}+\ldots \ldots+\beta_{\mathrm{n}} \mathrm{X}_{\mathrm{n}}$

The probability of an attitudinal category can be expressed as $P($ Attitudes $\leq j \mid \mathrm{X}$ ) where $X$ is the explanatory variable; $\alpha_{j}$ is the intercept; and $\beta_{\mathrm{n}}=\beta_{1}, \beta_{2}, \ldots \beta_{\mathrm{n}}$ are regression coefficients.

Education: how long the respondent received formal education;

Household perception: the mean score for cost and benefit perception at the household level;

Community perception: the mean score for cost and benefit perception at the community

Income: $\ln$ (the household income of the respondent in one year).

To test collinearity among independent variables, we calculated the variance 
285

inflation factors (VIFs), where VIFs $<4$ implies absence of collinearity (O'Brien 2007). Model 1 included all above independent variables, while "income" was excluded in Model 2. The sample size was smaller for Model $1(N=63)$ than for Model $2(N=75)$ because 12 respondents did not report their income clearly.

We set alpha at 0.05 . We entered and coded data using MS Excel and conducted statistical analysis using SPSS 20.0 software.

\section{Ethical note}

We collected data in accordance with the legal requirements of People's Republic of China, and with the permission of the Guizhou Forestry Department, Mayanghe National Nature Reserve Administration, and Qinglong village Committee. We read each interviewee a statement explaining the scientific purpose of our survey and requested and obtained their permission to participate in the interview process, including their permission to audio record the interview.

\section{RESULTS}

\section{Socio-demographic information}

We obtained socio-demographic information for 105 households in Qinglong village (Table 1). 502 residents, including 261 males and 241 females, lived in the 105 households. The mean household size was $5 \pm$ SD 2 people. The mean age of 105 
respondents was $48 \pm$ SD 15 years old. Although Tujia people only account for $47 \%$ of the population in MNNR, all respondents in this study were Tujia people. Overall, the education level in the community was low and the mean annual income of each household was about 32,359 CNY ( US\$ 5,123) in 2014.

Table 1 Socio-demographic composition of all respondents and those who finished the survey in Qinglong village, Mayanghe National Nature Reserve, China, March to August 2015

\begin{tabular}{|c|c|c|c|c|}
\hline \multirow{2}{*}{$\begin{array}{l}\text { Demographic } \\
\text { Variables }\end{array}$} & \multicolumn{2}{|l|}{ Mean \pm SD } & \multicolumn{2}{|c|}{$\%$ (number) of respondents } \\
\hline & $\mathrm{All}^{\mathrm{a}}$ & $\begin{array}{c}\text { Finished the } \\
\text { survey }^{b}\end{array}$ & $\mathrm{All}^{\mathrm{a}}$ & $\begin{array}{c}\text { Finished the } \\
\text { survey }^{\mathrm{b}}\end{array}$ \\
\hline Age & $48 \pm 15(105)$ & $48 \pm 14(75)$ & & \\
\hline Gender & & & & \\
\hline Male & & & $59(62)$ & $67(50)$ \\
\hline Female & & & $41(43)$ & $33(25)$ \\
\hline
\end{tabular}

\begin{tabular}{|c|c|c|c|c|}
\hline Family size & $5 \pm 2(105)$ & $5 \pm 2(75)$ & & \\
\hline \multicolumn{5}{|l|}{ Education } \\
\hline None & & & $35(37)$ & $29(22)$ \\
\hline Primary school (1-6 & & & $31(32)$ & $32(24)$ \\
\hline years) & & & $27(28)$ & $28(21)$ \\
\hline Middle school (6-9 & & & $8(8)$ & $11(8)$ \\
\hline \multicolumn{5}{|l|}{ years) } \\
\hline \multirow{2}{*}{\multicolumn{5}{|c|}{$\begin{array}{l}\text { Higher level (> } 9 \\
\text { years) }\end{array}$}} \\
\hline & & & & \\
\hline Annual Income in & $32359 \pm$ & $32791 \pm$ & & \\
\hline $2014^{\mathrm{c}}$ & 35269 & 35039 & & \\
\hline (CNY) & (91) & (63) & & \\
\hline
\end{tabular}

${ }^{\mathrm{a}}$ Including all households who finished the description of socio-demographic factors in the questionnaire $(N=105)$.

${ }^{\mathrm{b}}$ Including all households who finished both the description of socio-demographic factors and questions about attitudes and perceptions $(N=75)$.

${ }^{\mathrm{c}}$ Effective sample size (not all households reported annual income: $N=91$ or $N=63$ ). 

limitations on time and the lower desire to participate by local women.

\section{Attitudes towards langurs} among respondents in Qinglong village in Mayanghe National Nature Reserve, China,

\begin{tabular}{|c|c|c|c|c|c|}
\hline Category of perceived cost and benefit ${ }^{a}$ & $\begin{array}{l}\text { Reason types and key description of the answers } \\
\text { (original in Chinese) }\end{array}$ & $\begin{array}{l}\text { Positive } \\
\text { attitude } \\
N=33\end{array}$ & $\begin{array}{l}\text { Negative } \\
\text { attitude } \\
N=19\end{array}$ & $\begin{array}{l}\text { Neutral } \\
\text { attitude } \\
N=14\end{array}$ & $\begin{array}{l}\text { Total }^{\text {b }} \\
N=66\end{array}$ \\
\hline $\begin{array}{l}\text { Tangible Benefits: Those where the } \\
\text { respondent receives direct monetary benefits } \\
\text { due to the presence of the species on their }\end{array}$ & $\begin{array}{l}\text { 1. Langurs bring “luck”, improve personal income (享 } \\
\text { 猴子的“福”或个人致富), attract investments (带来 } \\
\text { 资金) }\end{array}$ & $\begin{array}{c}11 \\
(33 \%)\end{array}$ & $\begin{array}{c}0 \\
(0 \%)\end{array}$ & $\begin{array}{c}1 \\
(7 \%)\end{array}$ & $\begin{array}{c}12 \\
(18 \%)\end{array}$ \\
\hline $\begin{array}{l}\text { land: hunting fees or hunting for meat, langurs } \\
\text { tourism, financial compensation programs, }\end{array}$ & $\begin{array}{l}\text { 2. Attracting tourists, making their village a bustling } \\
\text { place (带来游客，闹热，外来人会来玩) }\end{array}$ & $\begin{array}{c}5 \\
(15 \%)\end{array}$ & $\begin{array}{l}0 \\
(0 \%)\end{array}$ & $\begin{array}{c}3 \\
(21 \%)\end{array}$ & $\begin{array}{c}8 \\
(12 \%)\end{array}$ \\
\hline $\begin{array}{l}\text { development projects (e.g. infrastructure } \\
\text { building), subsidies for implementing }\end{array}$ & $\begin{array}{l}\text { 3. More infrastructures and/or better roads, etc. (搞建 } \\
\text { 设, 修路等) }\end{array}$ & $\begin{array}{c}4 \\
(12 \%)\end{array}$ & $\begin{array}{c}0 \\
(0 \%)\end{array}$ & $\begin{array}{c}1 \\
(7 \%)\end{array}$ & $\begin{array}{c}5 \\
(8 \%)\end{array}$ \\
\hline mitigation measure, or reputation. & $\begin{array}{l}\text { 4. International recognition, media attention, proud of } \\
\text { François' langur (国际重视或外来人知道, 村子因 } \\
\text { 为黑叶猴可以上电视, 以黑叶猴为傲) } \\
\text { 5. Direct financial compensation for crops losses (农作 } \\
\text { 物损失经济补偿) }\end{array}$ & $\begin{array}{c}3 \\
(9 \%) \\
0 \\
(0 \%)\end{array}$ & $\begin{array}{c}0 \\
(0 \%) \\
0 \\
0 \%) \\
\end{array}$ & $\begin{array}{c}1 \\
(7 \%) \\
2 \\
(14 \%)\end{array}$ & $\begin{array}{c}4 \\
(6 \%) \\
2 \\
(3 \%)\end{array}$ \\
\hline $\begin{array}{l}\text { Intangible Benefits: Indirect benefits as } \\
\text { perceived by the respondent, such as positive }\end{array}$ & 6. Lovable （可爱） & $\begin{array}{c}5 \\
(15 \%)\end{array}$ & $\begin{array}{c}0 \\
(0 \%)\end{array}$ & $\begin{array}{c}1 \\
(7 \%)\end{array}$ & $\begin{array}{c}6 \\
(9 \%)\end{array}$ \\
\hline aesthetic/emotional/cultural value or & 7. Humans and animals have a close relationship in & 1 & 0 & 0 & 1 \\
\hline
\end{tabular}




\begin{tabular}{|c|c|c|c|c|c|}
\hline \multirow{7}{*}{$\begin{array}{l}\text { ecosystem services of species (e.g. } \\
\text { environmental quality, education). }\end{array}$} & general (人与动物有密切的关系) & $(3 \%)$ & $(0 \%)$ & $(0 \%)$ & $(2 \%)$ \\
\hline & 8. Beautiful, acrobatic, with graceful postures (好看, & 7 & 0 & 1 & 8 \\
\hline & 飞跳美观，姿势优美） & $(21 \%)$ & $(0 \%)$ & $(7 \%)$ & $(12 \%)$ \\
\hline & & 7 & & 1 & 8 \\
\hline & 9. Good or runny to play witn (好巩, 好管) & $(21 \%)$ & $0(0 \%)$ & $(7 \%)$ & $(12 \%)$ \\
\hline & & 1 & 0 & 0 & 1 \\
\hline & 10. & $(3 \%)$ & $(0 \%)$ & $(0 \%)$ & $(2 \%)$ \\
\hline \multicolumn{6}{|l|}{ Tangible Costs: Those where the respondent } \\
\hline 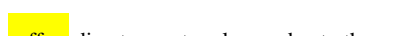 & 11. Conflicts; troublemaking animal (猴子生活到这个 & 0 & 6 & 1 & 7 \\
\hline 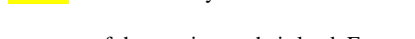 & 地方, 自己就生活不下去; 害兽, 讨嫌) & $(0 \%)$ & $(32 \%)$ & $(7 \%)$ & $(11 \%)$ \\
\hline instance, economical income losses such as & & 2 & 11 & 8 & 21 \\
\hline \multirow[t]{5}{*}{ crop or fruit loss, house damage by langurs. } & 12. Crop (corn) feeding (吃庄稼或吃玉米(苞谷)) & $(6 \%)$ & $(58 \%)$ & $(57 \%)$ & $(32 \%)$ \\
\hline & 13. Ransacking houses, damaging property and stealing & 0 & 5 & 5 & 10 \\
\hline & food (破坏房子, 翻房子, 进房子偷东西) & $(0 \%)$ & $(27 \%)$ & $(36 \%)$ & $(15 \%)$ \\
\hline & & 0 & 1 & 0 & 1 \\
\hline & & $(0 \%)$ & $(5 \%)$ & $(0 \%)$ & $(2 \%)$ \\
\hline \multicolumn{6}{|l|}{ Intangible Costs: Indirect cost as perceived by } \\
\hline \multicolumn{6}{|l|}{ the respondent, such as individual } \\
\hline psychological costs of fear, danger from & & 0 & 0 & 0 & 0 \\
\hline species, negative aesthetic/cultural value as & & $(0 \%)$ & $(0 \%)$ & $(0 \%)$ & $(0 \%)$ \\
\hline \multicolumn{6}{|l|}{ well as negative health impact, opportunity } \\
\hline \multicolumn{6}{|l|}{ and transaction costs. } \\
\hline \multirow[t]{4}{*}{ Neither costs nor benefits } & & 0 & 0 & 3 & 3 \\
\hline & & $(0 \%)$ & $(0 \%)$ & $(21 \%)$ & $(5 \%)$ \\
\hline & & 0 & 0 & 2 & 2 \\
\hline & 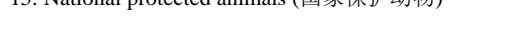 & $(0 \%)$ & $(0 \%)$ & $(14 \%)$ & $(3 \%)$ \\
\hline
\end{tabular}

${ }^{a}$ For conceptual clarity and categories of specific reasons in this paper, we referred to Kansky and Knight (2014) and the local context.

${ }^{\mathrm{b}}$ Effective number of respondents equals 66. Respondents sometimes gave multiple reason types in a response, so total frequencies may

be higher than the number of respondents.

335 held favorable attitudes concerning living near the langurs mainly described tangible

337 langur tourism, and the most important intangible benefits related to cultural perceptions

338 such as aesthetic value and emotional connection to the langurs (Table 2). 
"when monkeys become more, the village becomes richer and our area develops". One senior respondent even said, "we are getting good luck from langurs. If there were no monkeys in our village, some young men here would not be able to find a wife". Another respondent thought the existence of langurs can bring some other "economic benefits and development". As one respondent said, "the existence of langurs brings very limited income for my families, but it brings much more benefits to our area". These reasons were mainly divided into three types: attraction for tourists (e.g. "the visitors from outside come (to our village) because of the langurs"), infrastructure construction for tourism (e.g. "if no monkeys, the road here cannot be built better"), and the reputation of the place (e.g. "our village is getting more famous", “our area was shown on TV”, “we are proud of the langur”) (Table 2 and Fig. 2 c-d).

Local people enjoyed seeing François' langurs (Table 2). For instance, a few respondents described the reasons why they liked the langurs: "langur is a beautiful animal", "graceful jumping postures of monkeys", "when monkeys jumped on the trees, they are more beautiful than a dance". Emotional responses ("langur is a lovable animal") and cultural interactions such as "good or fun to play with" are also important reasons to shape local positive attitudes towards the langurs. Two respondents felt that crop feeding by langurs was not serious and they still had a positive attitude to the langurs. One respondent said "(the langurs) just fed on little crops, no big deal. They benefit us", while the other one thought the "monkey can bring us luck. Although they feed on crops, they are still good for us". In addition, one respondent claimed that the intangible benefits have the potential to turn into tangible benefits. She liked langurs because they are beautiful but went on to say 
that "people from outside need to spend money to come here and watch them".

Only one negative respondent was unable to clearly articulate the reason for her response. Negative attitudes primarily related to tangible costs of the langurs' presence such as crop or fruit feeding, destruction of house and property, or negative interactions between people and langurs (Table 2, Fig. 2 e-f). Some respondents said that they disliked the langurs because langurs fed on their corn and one respondent complained that "I worked so hard for my crops. However, the langurs can eat the crop and nobody provides financial compensation for my economic losses". Other human-langur interactions (e.g. damaging house, fruit feeding) also shape local attitudes in Qinglong village. A few respondents said, "langurs are hateful because they can damage our house and enter our house to search for food". The strongest expression from one respondent was that "I cannot survive here because of the existence of these langurs here".

Of neutral respondents, one was unable to articulate the reason for her response.

Over half of neutral respondents claimed that the presence of langurs in the village resulted in a trade-off with good and bad aspects $(N=9)$. For instance, one respondent said, "I like the langur because the langurs can attract the tourists to visit our village and I can get some economic benefit from this. I dislike them because they feed on my crops." Another respondent told us: "I like the langurs because these animals are beautiful while I dislike them because they feed on my crops and damaged my house". One of respondents connected her attitude with local financial compensation. She said that "I would like the langurs if my economic losses were compensated; otherwise, I dislike the langurs." Three other respondents thought that there were neither costs nor benefits of co-existing with 
385

langurs. Two men said "I like the langurs because these animals are listed as national protected animals while I hate them because they feed on my crops".

\section{Local perceptions of costs and benefits}

Overall, the mean score for respondent perceptions of costs and benefits of living nearby the langurs is neutral $(0.1 \pm \mathrm{SD} 0.2, N=75)$. The mean perception of costs and benefits of langurs at the household level (Table 3, FL1, FL4, FL6-FL9) was slightly negative $(-0.3 \pm \operatorname{SD} 0.3, N=75)$ while at the community level (Table 3, FL2, FL3, FL5, FL10) it was positive $(0.7 \pm \mathrm{SD} 0.3, N=75)$. The most important benefits associated with the langurs included the reputation of their village the development of local tourism and the development of local infrastructure (Table 3). The most important costs associated with the langurs' presence included the impact on tree cutting in the mountain, personal economic income, and use of wildlife resources (e.g. hunting) in the forest (Table 3).

Table 3 Perceived benefits and costs of François' langurs (FL), Qinglong village, Mayanghe National Nature Reserve, China, March to August 2015

\begin{tabular}{|c|c|c|c|c|c|}
\hline Code & $\begin{array}{l}\text { Question in terms of specific interactions between human and } \\
\text { langur in local context }\end{array}$ & Positive & Negative & Neutral & Unsure \\
\hline FL4 & $\begin{array}{l}\text { Does the FL have any impact on the education of your next } \\
\text { generation? }\end{array}$ & $16 \%$ & $5 \%$ & $59 \%$ & $20 \%$ \\
\hline FL7 & $\begin{array}{l}\text { Does the FL have any impact on your use of wildlife resource (e.g. } \\
\text { hunting) from the forest? }\end{array}$ & $3 \%$ & $41 \%$ & $51 \%$ & $5 \%$ \\
\hline FL9 & Does the FL have any impact on grazing around your village? & $7 \%$ & $8 \%$ & $72 \%$ & $13 \%$ \\
\hline FL2 & Does the FL have any impact on the environment of your village? & $9 \%$ & $4 \%$ & $63 \%$ & $24 \%$ \\
\hline FL3 & Does the FL have any impact on the reputation of your village? & $88 \%$ & $0 \%$ & $3 \%$ & $9 \%$ \\
\hline FL5 & Does the FL have any impact on the development of local & $76 \%$ & $3 \%$ & $12 \%$ & $9 \%$ \\
\hline
\end{tabular}


infrastructure?

FL10 Does the FL have any impact on the development of local tourism?

$80 \%$

$1 \%$

$8 \%$

\section{Key predictors of attitudes towards the langurs}

Model 1 (with factor income) showed the same significant factors as Model 2

403

Table 4 Variables shaping respondents' attitudes to François' langurs in an ordinal regression model, Qinglong village, Mayanghe National Nature Reserve, China, March to August 2015

\begin{tabular}{|c|c|c|c|c|c|c|c|c|}
\hline \multirow[t]{2}{*}{ Variable } & \multicolumn{4}{|c|}{$\begin{array}{c}\text { Model } 1 \\
\text { (with income, } N=63 \text { ) }\end{array}$} & \multicolumn{4}{|c|}{$\begin{array}{c}\text { Model 2 } \\
\text { (without income, } N=75 \text { ) }\end{array}$} \\
\hline & $\begin{array}{l}\text { Estimate } \\
\text { (b) }\end{array}$ & $\begin{array}{c}\text { Standard } \\
\text { Error }\end{array}$ & $\begin{array}{l}\text { Odds } \\
\text { Ratio }\end{array}$ & $P$ & $\begin{array}{l}\text { Estimate } \\
\text { (b) }\end{array}$ & $\begin{array}{c}\text { Standard } \\
\text { Error }\end{array}$ & $\begin{array}{l}\text { Odds } \\
\text { Ratio }\end{array}$ & $P$ \\
\hline age & -0.07 & 0.03 & 0.94 & 0.025 & -0.09 & 0.03 & 0.92 & 0.001 \\
\hline income & 0.20 & 0.25 & 1.22 & 0.418 & & & & \\
\hline household perception & 3.36 & 1.14 & 28.82 & 0.003 & 3.80 & 1.10 & 44.70 & 0.001 \\
\hline community perception & 2.50 & 1.15 & 12.20 & 0.030 & 2.50 & 0.99 & 12.15 & 0.011 \\
\hline education & -0.09 & 0.34 & 0.91 & 0.793 & 0.01 & 0.33 & 1.01 & 0.977 \\
\hline gender $=0$ & -1.81 & 0.69 & 0.16 & 0.009 & -1.68 & 0.65 & 0.19 & 0.010 \\
\hline$(1=$ reference $)$ & & & & & & & & \\
\hline
\end{tabular}

Note: $-2 \log$ Likelihood $=100.5, \chi^{2}=28.1, \mathrm{df}=\quad$ Note: -2 Log Likelihood $=117.1, \chi^{2}=34.3, \mathrm{df}=5$,

6, $P=0.000$, Nagelkerke Pseudo R-Square $=0.41 \quad P=0.000$, Nagelkerke Pseudo R-Square $=0.42$ 
412

413

414

415

416

417

418

419

420

421

422

423

424

significantly associated with local residents' attitudes toward langurs; for one unit increase (i.e., going from 0 to 1 ) in the mean score for cost and benefit perception at the household level, the odds of positive attitude were 44.7 times greater than the combined negative and neutral categories (Table 4). Likewise, the langurs' impacts on cost and benefit perceptions at the community level were also significantly associated with local residents' attitudes toward langurs; for one unit increase in the mean score for cost and benefit perception at the community level, the odds of positive attitude were 12.15 times greater than the combined negative and neutral categories, when we held the other variables in the model constant. In general, perceived benefit at household or community levels increased the likelihood of local people having a positive attitude toward langurs. Age was also significantly associated with local residents' attitudes toward langurs. As the age of respondent increased by one year, the probability of having a more positive attitude toward langurs decreased by $8 \%$, after controlling for the effects of other variables in the model. Gender was significantly associated with local residents' attitudes to langurs; for women the odds of having a more positive attitude toward the langurs were lower by $81 \%$ than for men, holding other variables in the model constant.

\section{DISCUSSION}

\footnotetext{
Overall, our results suggest that perceived costs and benefits explained local people's attitudes toward François' langurs well. Higher perceived benefits were associated with a more positive local attitude towards the langurs while higher perceived costs were
} 
433

associated with more negative attitudes. The results are similar to those in previous studies in that perceived costs and benefits are the main drivers of attitudes (e.g., Kansky and Knight 2014; McLennan and Hill 2013). The results also showed that the perceived benefits and costs associated with langurs at the household level tended to be negative overall while those at the community level these perceptions were quite positive. This difference in positive and negative responses at the community and household levels appears to be a common pattern (Khatun et al. 2012; McLennan and Hill 2013; Sousa et al. 2014; Hardwick et al. 2017). For example, researchers found that local people regarded chimpanzees (Pan troglodytes) as a good "crop raider" at Bulindi in Uganda and Cantanhez National Park in Guinea-Bissau since they play both a positive (flagship for tourism) and a negative (crop feeding) role in the livelihoods of local people (McLennan and Hill 2013; Sousa et al. 2014).

\section{Key costs of living with the langurs and attitudes towards the langurs}

The costs of living with a species are important in explaining attitudes towards large mammals (Kansky and Knight 2014). However, the relative importance of the four sub-categories of costs and benefits likely vary across different animal species. Intangible costs (i.e., fear) of living with species perceived to be dangerous may be more important than other factors in shaping people's attitudes towards large mammals (Kansky and Knight 2014). In our study, intangible costs were not a strong predictor of local attitudes toward François' langurs. This could be because langurs are less aggressive than the larger mammals in other studies (Campbell-Smith et al. 2010; Hockings et al. 2010; Kansky and Knight 2014). 
Meanwhile, the intangible opportunity costs of living with damage-causing wildlife also influence wildlife conservation (Barua et al. 2013). In this study, tree cutting in the mountain, personal economic income, and use of wildlife resources in the forest were three important perceived costs that local people associated with langurs at the household level. However, these negative perceptions appeared to explain local attitudes toward langurs unevenly. No respondent mentioned opportunity costs relating to wood and wildlife resources as reasons for their attitudes towards langurs.

We found that langur crop-feeding related to personal economic income (Tangible Costs) is the top factor explaining the negative attitude of local people towards langurs in Qinglong village. This result is not surprising. Local residents' economic losses from crop-feeding can detract from the community support of species conservation. Crop-feeding by primates causes negative interactions between primates and local people in many areas (e.g. Hill 2000, 2005; Khatun et al. 2013; Lee and Priston 2005; McLennan and Hill 2013; Sousa et al. 2014). We also found that property destruction caused by langurs and simply living in the same area as langurs were linked to negative attitudes in Qinglong village. Crop-feeding, houses and property destruction were most likely to cause respondents' household economic losses, and were linked to negative perceptions and attitudes of local residents.

Two respondents felt that crop feeding by langurs was not serious as they only fed on crops with a low economic value. Economic losses such as crop-feeding by some primate species are not always a significant factor driving negative sentiments in local farmers (Khatun et al. 2012; Radhakrishna 2017). Different levels of crop damage lead to varied 
attitudes to langur in local people.

\section{Benefits of living with the langurs and attitudes towards the langurs}

We found that the cost and benefit perceptions of living with the langurs at the community level is very positively and significantly related to local peoples' attitudes towards the langurs. Among these perceptions, the impact of langurs on the development of local tourism (Tangible Benefits) has the most important potential. 80\% of the respondents thought the existence of langurs is good for local tourism development. Langur-related tourism has multiple benefits in Qinglong village, including bolstering the local economy and improving village reputation and infrastructure. This is similar to previous studies that suggest local tourism associated with flagship wildlife species positively affected local attitudes toward wildlife (Sekhar 2003; Waylen et al. 2009; Khatun et al. 2012; Sousa et al. 2014). In particular, primate tourism has delivered measurable economic benefits, funding for conservation activities, improved agricultural markets, and likely improved attitudes towards conservation in some countries (e.g. Uganda, Hvenegaard 2014; Uganda, McLennan and Hill 2013; Guinea-Bissau, Sousa et al. 2014; China, Xiang et al. 2011). Kansky and Knight (2014) suggested that tangible benefits may be more important in explaining attitudes towards species that generate larger contributions to livelihoods. The human-langur relationship may be improved through tangible benefit sharing such as public investment in the local community and species related-tourism development. Caution, however, is required, as tourism infrastructure can contribute to the destruction and fragmentation of the langurs' 
497

habitat. MNNR administration should work with local governments to minimize the impact of infrastructure construction (Fyumagwa et al. 2013).

While some studies have shown a positive association between wildlife tourism and attitudes, some researchers argue that it may not result in positive conservation behaviors toward wildlife (e.g. Sekhar 2003; Waylen et al. 2009) and may even contribute to socio-ecological problems that further harm conservation efforts (Desmond and Desmond 2014; Liu et al. 2012, 2016; Russon and Susilo 2014; Russon and Wallis 2014). For example, the relationship between local residents and protected area and tourism management bodies may change as tourism develops (Liu et al. 2016). Local people might be positive at the early stage of local tourism development since they have obtained or seen some benefits (Ellwanger et al. 2015; Xu et al. 2006, 2009); but as tourism develops, local residents often benefit from tourism disproportionally, with the poorer benefiting less, such as in the Wolong National Nature Reserve (Liu et al. 2012, 2016; Sekhar 2003; Xu et al. 2006, 2009). In the case of MNNR, although the majority of Qinglong village residents have not yet received significant economic benefits from langur-related tourism, local people perceived the existence of langurs as a major attraction and thus had high expectations of future tourism development (and potential benefit). However, this high expectation may lead to a higher management risk if it cannot be met in the near future. Only a small proportion of local population can benefit directly from ecotourism (Liu et al. 2016). The lack of direct participation or the unequal distribution of economic benefits in the long run may result in negative attitudes toward the nature reserve (Hvenegaard 2014; Xu et al. 2006; Liu et al. 2016). In our study, we found that only $4 \%$ of residents claimed that they currently benefited economically because of the 
519

existence of the langurs. This point might be explained by the current development of local tourism in Qinglong village. Although more and more tourists came to this village for langur watching, these visitors had free to access Qinglong village and most spent just half a day watching the langurs then drove to the city for lodging and food (author's personal observation). Thus, their expenditure in Qinglong village was very limited. Local investments in the tourism industry are limited because of the low financial capacity of local residents. Future policy should combine the goal of species conservation and poverty alleviation, for example by providing training in tourism services to local people. Meanwhile, similar to guidelines for best practice in great ape tourism (Williamson and Macfie 2014), the government and local community can consider developing langur-watching ecotourism guidelines in a responsible way to ensure a better balance between species conservation and local economic development.

In addition to the benefits of langur-related tourism, intangible benefits such as positive emotions and aesthetic values might positively influence the relationship between humans and langurs. Intangible benefits may be more important for species that are particularly attractive or have high symbolic importance (Kansky and Knight 2014). Adjectives such as "beautiful" were used to describe the langurs. Similarly, in Tombali, south of Guinea-Bissau, aesthetic values (i.e. pretty or ugly) can be key components in determining people's attitude toward Guinea baboons (Papio papio) (Costa et al. 2013). Moreover, local residents also used "loveable" and "good or funny to play with" to describe interactions between human and langurs in our study. This suggests that local residents have a good emotional disposition toward François' langur, which can be an important factor in people's 
541

response to wildlife (Jacobs et al. 2012). This positive emotional disposition toward the langurs may have its roots in traditional Chinese culture (Jacobs et al. 2012; Cui et al. 2012; Kansky and Knight 2014; Zhang 2015). The Chinese believe that both people and monkeys benefit from interacting which results in harmony (Chang 2001). In this case, a "good" emotional disposition supports positive local attitudes towards the François' langur. Future research on aesthetic and emotional interactions between humans and langurs would help to better understand the influence of intangible benefits on local attitudes in MNNR. Simultaneously, interactive with langurs has a potential risk of anthroponotic disease transmission from human to langurs (Wallis and Lee 1999; Muehlenbein and Wallis 2014).

\section{Trade-off between costs and benefits and attitudes towards the langur}

We found a trade-off between costs and benefits shaping local attitudes toward langurs. On the one hand, some respondents viewed a trade-off between tangible benefits and tangible costs. For instance, one respondent liked the langurs because they can attract tourists to visit the village and lead to economic benefits; however, she disliked them because they fed on her crops. Previous studies have also linked tangible costs and benefits to explain local attitudes toward species (Khatun et al. 2012; McLennan and Hill 2013; Sousa et al. 2014). Sousa and colleagues (2014) considered that local perceptions of chimpanzees might be driven by not only crop feeding but also by the benefits of species tourism. In addition, direct financial compensation may play be a positive influence on local attitudes to species. However, only few respondents mentioned that direct financial compensation influenced their attitudes and one respondent complained that there is no 
563

564

565

566

567

568

569

570

571

572

573

574

575

576

577

578

579

compensation for crop losses. Therefore, direct financial compensation seems not to be an efficient or effective mean to counteract loss to influence local attitudes. Scientific evaluations of property losses and effective practices of financial compensation (e.g. sustainable financial source for compensation, transparent compensation policy, and timely payment for losses) should be conducted to reduce institutional vulnerabilities related to financial compensation (Setchell et al. 2017).

On the other hand, we found a trade-off between intangible benefits and tangible costs. Although we did not examine this quantitatively, our analysis showed that intangible benefits appeared to have an effect on local attitudes. While people favored the langurs due to their beauty, they disliked langurs because they fed on crops and damaged houses. This trade-off also appeared to be an important facet of local attitudes toward primates in previous studies (Costa et al. 2013; Lee and Priston 2005; Hill and Webber 2010; Sousa et al. 2014). For instance, several other studies have found that the human-like appearance and behavior of some primate species can contribute to positive attitudes, while crop-raiding makes people perceive animals as pests (Costa et al. 2013; Dore et al. 2018a; Hill and Webber 2010).

\section{Key demographic factors and attitudes towards the langurs}

wildlife both positively and negatively, depending on the cultural and historical context and the knowledge or experiences of these respective groups (e.g. Ellwanger et al. 2015; Kansky and Knight 2014; McLennan and Hill 2013; Sousa et al. 2014). For example, adults 
584

emphasized chimpanzee behavior and narratives about the shared history of humans and chimpanzees while young people emphasized morphological aspects of human-chimpanzee similarities in a study of human-chimpanzee relations (Sousa et al. 2014). In our case, the relationship between age and attitude toward langurs might stem from different historical experiences of langurs in older and younger people. The extent to which a person has interacted with a species is likely to be an important predictor of attitudes towards a species (Kansky and Knight 2014). According to one respondent, "before the reserved was established (1987); the langurs could be caught and sold. The price was up to $500 \mathrm{CNY}$ ( US\$ 80) per individual." Hunting might have been an important income source for some local people in the past. However, the law forbade langur hunting when reserve was created. Since then, the langurs have brought no direct economic benefits for those older residents. In contrast, the improvement of infrastructure and tourist attractions due to the development of langur-related tourism make it convenient for younger people to go to cities for work and brings opportunities to earn money in their village. Older people also have fewer income sources than younger people. Younger people prefer to go to the cities to earn money while older people might depend more on planting crops. After the langurs were protected and habituated to humans, they occurred near the village and fed on crops more frequently than before. This would bring relatively higher economic losses (crop feeding and property losses) and negative perceptions for older farmers, although we did not identify a direct and significant effect of local income level on local attitude.

Men's attitudes toward langurs in this study were more positive than those of women. This result is very similar to several studies in Myanmar and China (Allendorf and 
Allendorf 2013; Allendorf and Yang 2015). Researchers found that men are more likely to have a positive attitude toward protected areas and to perceive conservation and ecosystem service benefits than women and that gender differences in knowledge about the reserve contributed to the understanding of gendered perceptions of problems and benefits of the reserve (Allendorf and Allendorf 2013). In our case, local people's knowledge of the benefits of François' langurs in MNNR can be considered as knowledge of species ecosystem services and men might be more knowledgeable about these benefits due to their greater involvement in local management information communication in male-led households. A similar phenomenon has been described elsewhere in China (Allendorf and Yang 2015; Xu et al. 2006). Local women might be more familiar about a species' ecology since it seems that more females take care of farmland in the village (author's personal observation). Women are also more knowledgeable about the Guizhou snub-nosed monkeys (Rhinopithecus brelichi) than men in Fanjingshan National Nature Reserve in China (Ellwanger et al. 2015), which is not far from our study site. Gendered differences in roles and tasks might lead to a gendered difference in knowledge of costs and benefits, resulting in differences in the perceptions of and attitudes to langurs.

\section{CONCLUSION}

Qinglong village is one of 25 villages where the langurs occur within the reserve (Author, unpubl data). Future studies should cover the other villages and ethnic groups to better understand inter- and intra- village variations in human-langur relationships. This will 
provide more information to inform reserve-wide conservation management and community

development planning.

In this study, we highlight the importance of perceived costs and benefits in determining local attitudes toward langurs in Qinglong village of MNNR. We found that respondents with favorable attitudes associated the langurs mainly with tangible benefits and intangible benefits while those with negative attitudes associated the langurs with tangible costs. The respondents' cost and benefit perceptions at the household level were different from those at the community level but both are strongly related to local attitudes. These results indicated that local people's attitudes toward this species are constructed through a multifaceted set of interactions. This suggests that a sole focus on costs or benefits and at only one scale (i.e., household vs. community) may obscure critical information leading to an understanding of people's attitudes toward primates.

Crop feeding, house damage, and langur-related tourism are major factors influencing local attitudes toward langurs. It is important for conservation management officials to address these important trade-offs (i.e., property losses and langur-related tourism) and improve policies related to them to maximize the benefits to local communities while mitigating the costs of the langur to local livelihoods. Scientifically-informed tourism guidelines based on langur conservation must be outlined prior to industry development. The land use for infrastructure constructions within the nature reserve should also be strictly evaluated. The positive emotional connection and a local cultural context such as "good to play with langurs" in this study might have a negative outcome for langur conservation if managers do not provide proper interaction guidelines for local people and tourists. 
649

650

651

652

653

654

655

656

657

658

659

660

661

662

663

664

665

666

668

669

670

Biocultural conservation and education programs (for instance, storytelling) that embed a positive conservation message may be useful to change people's traditional cultural values of "playing with monkey" (Fernández-Llamazares and Cabeza 2017; Gavin et al. 2015; Niu et al. 2015). Meanwhile, guides and narrators for tourists should be trained for a more effective langur watching program. These programs should also involve local women and older adults since they more likely have negative attitudes to langurs.

This study is a snapshot of the human-langur relationship in MNNR. We identify proximate factors influencing local attitudes that are useful for conservation management. More in-depth investigation on how human and langurs interact across space and time, using an ethnoprimatological approach (Dore et al. 2018a, b; Fuentes and Hockings 2010), is needed to understand the root causes of the interconnections. Future research on langur foraging behavior, such as the prevalence of crop feeding, and ethnographic data on human-langur ecological overlap and cultural interconnections is urgently needed to protect the population of François' langurs. We suggest that research on socioeconomic patterns and people's attitudes towards primates should be conducted in protected areas like MNNR to understand the factors that shape human-primate interactions, as well as their changes, especially in the context of rapid economic and infrastructure development.

\section{REFERENCES}

Alexander, S. (2000). Resident attitudes towards conservation and black howler monkeys in Belize: The Community Baboon Sanctuary. Environmental Conservation, 27(4),

$$
341-350 \text {. }
$$


671 Abrams, R. W., Anwana, E. D., Ormsby, A., Dovie, D. B., Ajagbe, A., Abrams, A. (2009). 672 Integrating top-down with bottom-up conservation policy in Africa. Conservation $673 \quad$ Biology, 23(4), 799-804.

674 Adams, W. M., Aveling, R., Brockington, D., Dickson, B., Elliott, J., et al. (2004). Biodiversity 675 conservation and the eradication of poverty. Science, 3006, 1146-1149.

676 Allendorf, T. D. (2007). Residents' attitudes toward three protected areas in southwestern 677 Nepal. Biodiversity and Conservation, 16, 2087-2102.

678 Allendorf, T. D., Allendorf, K. (2013). Gender and attitudes toward protected areas in 679 Myanmar (Burma). Society \& Natural Resources, 26(8):962-976.

Allendorf, T. D., Yang, J. (2013). The role of ecosystem services in park-people relationships: The case of Gaoligongshan Nature Reserve in southwest China. Biological Conservation, 167:187-193.

683

Ajzen, I., Fishbein, M. (1980). Understanding attitudes and predicting social behavior. 595-646. 
693

694

695

696

697

698

699

700

701

702

703

704

705

706

707

708

709

710

711

712

713

conflict: health impacts, opportunity and transaction costs. Biological Conservation, 157(1), 309-316.

Carter, N. H., Riley, S. J., Shortridge, A., Shrestha, B. K., Liu, J. G. (2014). Spatial assessment of attitudes toward Tigers in Nepal. Ambio, 43(2), 125-137.

Campbell-Smith, G., Simanjorang, H. V., Leader-Williams, N., Linkie, M. (2010). Local attitudes and perceptions toward crop-raiding by orangutans (Pongo abelii) and other primates in northern Sumatra, Indonesia. American Journal of Primatology, 72(10), 866-876.

Ceballos, G., Ehrlich, P. R., Barnosky, A. D., García, A., Pringle, R. M., et al. (2015). Accelerated modern human-induced species losses: Entering the sixth mass extinction. Science Advance, 1(5), e1400253.

Chalise M. K., Johnson R. L. (2015). Farmer attitudes toward the conservation of "pest" monkeys: The view from Nepal. In Paterson J.D., Wallis J. (eds.). Commensalism \& conflict: the human-primate interface. Winnipeg, Manitoba: Hignell Printing, 222-238.

Chen, B., Hu, G., Luo H.Z., Cao, Y., Yang J. L.(2012). Winter Food Overlap between Grazing Goats and Francois's Langurs in Mayang Nature Reserve of Guizhou. Sichuan Journal of Zoology, 31(6): 853-857.

Cui, Q. M., Xu, H. G., Geoffrey, W. (2012). A cultural perspective on wildlife tourism in China. Tourism Recreation Research, 37(1), 27-36.

Chang, J. (2001). Chinese zodiac culture. Shanghai. Shanghai Dictionary Press (In Chinese).

Corlett, R. T. (2015). The Anthropocene concept in ecology and conservation. Trends in Ecology \& Evolution, 30, 36-41. 
715

Costa, S., Catarina, C., Claudia, S., Phyllis, L. (2013). The Good, The Bad and The Ugly: Perceptions of Wildlife In Tombali (Guinea-Bissau, West Africa). Journal of Primatology, 2, 110.

De Boer, W., Baquete, D. S. (1998). Natural resource use, crop damage and attitudes of rural people in the vicinity of the Maputo Elephant Reserve, Mozambique. Environmental Conservation, 25 (3), 208-218.

Desmond, J. S., Desmond, J. A. Z. (2014). Evaluating the effectiveness of chimpanzee tourism, in Russon, A.E. and Wallis, J. (eds.) Primate Tourism: A Tool for Conservation? Cambridge: Cambridge University Press, 199-212.

Dore, K. M., Eller, A. R., Eller, J. L. (2018a). Identity Construction and Symbolic Association in Farmer-Vervet Monkey (Chlorocebus aethiops sabaeus) Interconnections in St. Kitts. Folia Primatologica, 89(1), 63-80.

Dore, K. M., Radford, L., Alexander, S., Waters, S. (2018b). Ethnographic Approaches in Primatology. Folia Primatologica, 89, 5-12.

Estrada, A., Garber, P. A., Rylands, A. B., Roos, C., Fernandez-Duque E., et al. (2017). Impending extinction crisis of the world's primates: why primates matter. Science Advance, 3:e1600946

Ellwanger, A. L., Riley, E. P., Niu, K., Tan, C. L. (2015). Local people's knowledge and attitudes matter for the future conservation of the endangered Guizhou Snub-Nosed Monkey (Rhinopithecus brelichi) in Fanjingshan National Nature Reserve, China. International Journal of Primatology, 36(1), 33-54.

Ellwanger, A. L., Riley, E. P., Niu, K., Tan, C. L. (2017). Using a mixed-methods approach 
to elucidate the conservation implications of the human-primate interface in Fanjingshan National Nature Reserve, China. In Kerry M.D., Riley E.P., Fuentes A. (eds.). Ethnoprimatology: A Practical Guide to Research at the Human-Primate Interface (1st edition). Cambridge: Cambridge University Press, 257-270.

Fernández-Llamazares, álvaro, \& Cabeza, M. (2017). Rediscovering the potential of indigenous storytelling for conservation practice. Conservation Letters, 11(3), 1-12.

Fyumagwa, R. D., Gereta, E. J., Hassan, S., Kideghesho, J. R., Kohi, E. M., et al. (2013) Roads as a Threat to the Serengeti Ecosystem. Conservation Biology, 27(5),1122-1125.

Fuentes, A., Hockings, K. J. (2010). The ethnoprimatological approach in primatology. American Journal of Primatology, 72(10), 841-847.

Gavin, M. C., McCarter, J., Mead, A., Berkes, F., Stepp, J. R., et al. (2015). Defining biocultural approaches to conservation. Trends in ecology \& evolution, 30(3), 140-145.

Hardwick, J. L., Priston, N. E. C., Martin, T. E., Tosh D. G., Mustari A. H., et al. (2017). Community Perceptions of the Crop-Feeding Buton Macaque (Macaca ochreata brunnescens): an Ethnoprimatological Study on Buton Island, Sulawesi. International Journal of Primatology, 38(6), 1102-1119..

He, Q., Wu, Z., Zhou, W., Dong, R. (2011). Perception and attitudes of local communities towards wild elephant-related problems and conservation in Xishuangbanna, southwestern China. Chinese Geographical Science, 21, 629-636.

Hill, C. M. (2000). Conflict of interest between people and baboons: crop raiding in Uganda. International Journal of Primatology, 21, 299-315.

Hill, C. M. (2005). People, crops and primates: a conflict of interests. In Paterson J. D., Wallis 
J. (eds.). Commensalism \& conflict: the human-primate interface. Winnipeg, Manitoba: Hignell Printing, 40-59.

Hockings, K. J., Yamakoshi, G., Kabasawa, A., Matsuzawa, T. (2010). Attacks on local persons by chimpanzees in Bossou, Republic of Guinea: long-term perspectives. American Journal of Primatology, 72(10), 887-896.

Hu, G., Dong, X., Wei, Y., Zhu, Y., Duan, X. H. (2004). Evidence for a decline of François' langur Trachypithecus francoisi in Fusui Nature Reserve, south-west Guangxi, China. Orxy, 38(1), 48-54.

Hvenegaard, G. T. (2014). Economic aspects of primate-focused tourism associated with primate conservation. In Russon A. E., Wallis J. (eds.), Primate Tourism: A Tool for Conservation? Cambridge, UK: Cambridge University Press, 259-277.

Jacobs, M. H., Vaske, J. J., Roemer, J. M. (2012). Toward a Mental Systems Approach to Human Relationships with Wildlife: The Role of Emotional Dispositions. Human Dimensions of Wildlife, 17(1), 4-15.

Jiang, Z. G., Li, L. L., Luo, Z. H., Tang, S. H., Li, C. W., et al. (2016). Evaluating the status of China's mammals and analyzing their causes of endangerment through the red list assessment. Biodiversity Science, 24(5), 552-567. (in Chinese with English abstract)

Jiang Z. G., Liu S. Y, Wu Y., Jiang X. L., Zhou K. Y. (2017). China's mammal diversity. Biodiversity Science, 25(8), 886-895. (in Chinese with English abstract)

Kansky, R., Knight, A. T. (2014). Key factors driving attitudes towards large mammals in conflict with humans. Biological Conservation, 179, 93-105.

Kansky, R., Kidd, M., Knight, A. T. (2014). Meta-analysis of attitudes toward damage-causing 
mammalian wildlife. Conservation Biology, 28, 924-938.

Khatun, U. H., Ahsan M. F., Røskaft E. (2012). Attitudes of the local community towards the conservation of the common langur (Semnopithecus entellus) in Keshabpur, Bangladesh. International Journal of Biodiversity and Conservation, 4(11), 385-399.

Knight, J. (1999). Monkeys on the move: the natural symbolism of people-macaque conflict in Japan. The Journal of Asian Studies, 58, 622-647.

Lee, P. C., Priston, N. E. C. (2005). Human attitudes to primates: perceptions of pests, conflict and consequences for conservation. In Paterson J. D., Wallis J. (eds.). Commensalism \& conflict: the human-primate interface. Winnipeg, Manitoba: Hignell Printing, 1-23.

Li, B., Li, M., Li, J., Fan, P., Ni, Q., et al. (2018). The primate extinction crisis in China: immediate challenges and a way forward. Biodiversity and conservation, 27, 3301-3327.

Li, Y. B., Huang, C. M., Ding, P., Tang, Z., Wood, C. (2007). Dramatic decline of François' langur Trachypithecus francoisi in Guangxi Province, China. Orxy, 41(1), 38-43.

Linnell, J. D. C., Rondeau, D., Reed, H., Williams, R., Altwegg, R., et al. (2010). Confronting the costs and conflicts associated with biodiversity. Animal Conservation, 13, 429-431.

Liu, W., Vogt, C. A., Lupi, F., He, G. (2016). Evolution of tourism in a flagship protected area of China. Journal of Sustainable Tourism, 24(2), 203-226.

Liu, W., Vogt, C. A., Luo, J., He, G., Frank, K. A., Liu, J. (2012). Drivers and socioeconomic impacts of tourism participation in protected areas. PLOS ONE, 7: e35420.

Manfred, M. (1991). Human Scale Development: Conception, application and further reflections. New York: The Apex Press. 
803

804

805

806

807

808

809

810

811

812

813

814

815

816

817

818

819

820

821

822

823

824

Manfredo, M. J., Bright, A. D. (2008). Attitudes and the Study of Human Dimensions of Wildlife. Who Cares About Wildlife? New York: Springer, 75-109.

Maslow, A. H. (1943). A Theory of Human Motivation. Psychological Review, 50(4), 370-396.

McLennan, M. R., Hill, C. M. (2012). Troublesome neighbours: Changing attitudes towards chimpanzees (Pan troglodytes) in a human-dominated landscape in Uganda. Journal for Nature Conservation, 20, 219-227.

Nadler, T., Thanh, V. N., Streicher, U. (2007). Conservation status of Vietnamese primates. Vietnamese Journal of Primatology, 1(1), 7-26.

Nepal, S.K. (2002). Involving indigenous peoples in protected area management: comparative perspectives from Nepal, Thailand, and China. Environmental Management, 30, $748-763$.

Niu, K., Tan, C. L., Cui, D., Chen, S., \& Shi, L. (2015). Xingda's wildlife explorations in Fanjingshan. Guiyang: Guizhou Science and Technology Press, 1-90.

Niu, K., Xiao, Z., Wang, B., Yang, D., Tan, C. L., et al. (2016). Population estimates and distribution of François' Langurs (Trachypithecus francoisi) in Mayanghe National Nature Reserve, China. Chinese Journal of Zoology, 51(6), 925-938.

O'Brien, R. M. (2007). A caution regarding rules of thumb for variance inflation factors. Quality \& Quantity, 41 (5), 673-690.

Overall plan on the development and management of national parks (2017) http://www.gov.cn/zhengce/2017-09/26/content_5227713.htm (Accessed 02 October 2017) 
825

Radhakrishna, S. (2017). Culture, Conflict, and Conservation: Living with Primates in Northeastern India. In Kerry M.D., Riley E., Fuentes, A. (eds.), Ethnoprimatology: A Practical Guide to Research at the Human-Primate Interface (1st edition). Cambridge: Cambridge University Press, 271-283.

Rands, M. R. W., Adams, W. M., Bennun, L., Butchart, S. H. M., Clements, A., et al. (2010). Biodiversity conservation: Challenges beyond 2010. Science, 329, 1298-1303.

Riley, E. P., Priston, N. E. (2010). Macaques in Farms and Folklore: Exploring the Human-Primate Interface in Sulawesi, Indonesia. American Journal of Primatology, 72(10), 848-854.

Rocha, L. C., Fortes, V. B. (2015). Perceptions and attitudes of rural residents towards Capuchin monkeys, in the area of influence of the Dona Francisca Hydroelectric power plant, south Brazil. Ambiente \& Sociedade, 18(4), 19-34.

Russon, A., Wallis, J. (2014). Primate tourism as a conservation tool: A review of the evidence, implications, and recommendations. In: Russon A. and Wallis J, (eds.). Primate Tourism: A Tool for Conservation? Cambridge, UK: Cambridge University Press, 313-332.

Russon, A. E., Susilo, A. (2014). Orangutan tourism and conservation: 35 years' experience. in Russon, A. E. and Wallis, J. (eds.) Primate Tourism: A Tool for Conservation?. Cambridge: Cambridge University Press, 76-97.

Sekhar, N. U. (2003). Local people's attitudes towards conservation and wildlife tourism around Sariska Tiger Reserve, India. Journal of Environmental Management, 69(4), $339-347$. 
Setchell, J. M., Fairet, E., Shutt, K., Waters, S., Bell, S. (2017). Biosocial conservation: Integrating biological and ethnographic methods to study human-primate interactions. International Journal of Primatology, 38(2), 401-426.

Sousa, J., Vicente, L., Gippoliti, S., Casanova, C., Sousa, C. (2013). Local Knowledge and Perceptions of Chimpanzees in Cantanhez National Park, Guinea-Bissau. American Journal of Primatology, 76, 122-134.

Waylen, K. A., McGowan, P. J. K., Milnergulland, E. J. (2009). Ecotourism positively affects awareness and attitudes but not conservation behaviors: a case study at Grande Riviere, Trinidad. Oryx, 43(3), 343-351.

Williamson, E. A., Macfie, E. J. (2014). Guidelines for best practice in great ape tourism. In Russon, A. E. and Wallis, J. (eds.) Primate Tourism: A Tool for Conservation? Cambridge: Cambridge University Press, 292-310.

Wu, A. (2004). Food provision for wild François' langurs in Mayanghe Nature Reserve. Chinese Journal of Wildlife, 25, 37. (in Chinese)

Xiang, Z. F., Huo, S., Xiao, W., Cui, L. W. (2010). Positive influence of traditional culture and socioeconomic activity on conservation: A case study from the black-and-white snub-nosed monkey (Rhinopithecus bieti) in Tibet. Zoological Research, 31(6), 645-650.

Xiang, Z. F., Yu ,Y., Yang, M., Yang, J.Y., Niao, M. Y., et al.(2011). Does flagship species tourism benefit conservation? A case study of the golden snub-nosed monkey in Shennongjia national nature reserve. Chinese Science Bulletin, 24, 2553-2558.

Xu, J. Y., Chen, L. D., Lv, Y. H., Fu, B. J. (2006). Local people's perceptions as decision 

Journal of Environmental Management, 78, 362-372.

871 Xu, J., Lu, Y., Chen, L., Liu, Y. (2009). Contribution of tourism development to protected area management: local stakeholder perspectives. International Journal of Sustainable Development and World Ecology, 16:30-36.

874 Zhang, P. (2015). Good gibbons and evil macaques-A historical review on cognitive features 875 of non-human primates in Chinese traditional culture. Primates, 56(2), 215-225.

876 Zhu, J., Zhao, M., Wu, A., Zhang, Z. (2017). The analysis on natural resource protection and 877 community sustainable development of Mayanghe National Nature Reserve. In Gou, G. Q., Wei L. M., Xie S. X. (eds.), Biodiversity in Mayanghe National Nature Reserve, China. Guiyang: Guizhou Science and Technology Press, 571-582. 